\title{
Pemodelan Sistem Interaksi Obat dengan Menggunakan Fuzzy Inference System dan Pareto Optimality
}

\author{
Elena Yustina*1, Subanar $^{2}$ \\ ${ }^{1}$ Program Studi S2/S3 Ilkom, FMIPA, UGM, Yogyakarta \\ ${ }^{2}$ Jurusan Ilmu Komputer dan Elektronika, FMIPA UGM, Yogyakarta \\ e-mail:_*1elena4488@gmail.com, ${ }^{2}$ subanar@yahoo.com
}

\begin{abstract}
Abstrak
Interaksi obat merupakan interaksi yang terjadi antar obat yang di konsumsi secara bersamaan. Interaksi obat dapat menghasilkan efek baik terhadap pasien, namun tidak jarang menghasilkan efek buruk. Penderita penyakit hipertensi yang disertai diabetes diharapkan dapat mengontrol tekanan darah dan kadar gula darah agar tetap dalam keadaan normal, untuk itu perlu diperhatikan penggunaan obat untuk kedua penyakit tersebut agar menghasilkan terapi yang efektif.

Pareto optimality adalah konsep popular dalam penentuan solusi optimal masalah multi-objektif. Dalam menentukan solusi optimal masalah multi-objektif harus diperhatikan setiap fung si tujuan, tidak jarang fungsi tujuan bertentangan. Interaksi dua obat mempunyai dua fungsi tujuan yaitu memaksimalkan efek positif dan meminimalkan efek negatif, sehingga perlu dicari solusi optimal penggunaannya untuk mencapai terapi yang diharapkan. Penelitian ini menggunakan metode Fuzzy Inference Sistem (FIS) untuk menentukan obat yang sesuai untuk menjaga agar tekanan darah penderita penyakit hipertensi dan kadar gula darah penderita diabetes tetap terkontrol dalam keadaan normal serta pareto optimality dalam mencari solusi optimal penggunaan obat.

Fuzzy Inference System menghasilkan output pilihan golongan obat berdasarkan aturan-aturan fuzzy sesuai dengan kondisi penyakit pasien. Perhitungan optimasi dengan metode pareto optimality menghasilkan pasangan solusi untuk pemakaian obat diabetes dan hipertensi yang memenuhi batasan nilai kadar minimal efektif (Minimum Effective Concentration; MEC) dan kadar toksik maksimum (Minimum Toxic Concentration; MTC) masing-masing obat.
\end{abstract}

Kata kunci-Fuzzy Inference System, Pareto Optimality, Interaksi Obat

\begin{abstract}
Drug interactions is the interaction occurs between drugs that consumption simultaneously. Drug interactions can produce a good effect on patients, but not rarely produce adverse effects. Patients with diabetes and hypertension expected to control blood pressure and blood glucose levels to remain in normal circumstances, it is necessary to consider the use of medications for both diseases in order to produce effective therapies.

Pareto optimality is a popular concept in the determination optimal solution of multiobjective problems. In determining the optimal solution of multiobjective problem should pay attention for each objective function, frequently conflicting objective functions. The interaction of two drugs has two objective function that is maximizing the positive effects and minimize negative effects. So its use is necessary to find optimal solutions to achieve the expected therapeutic. This research using Fuzzy Inference Sistem (FIS) to determine the appropriate medication to keep blood pressure and blood glucose levels of patients with hypertension and diabetes under control in normal and Pareto optimality to determine drug optimal solution.

Fuzzy Inference System generates output choice of drug classes based on fuzzy rules in accordance with the patient's disease condition. Pareto optimality produces a pair solution for
\end{abstract}

Received February 22 $2^{\text {th }}, 2012 ;$ Revised March 15 $5^{\text {th }}, 2012$; Accepted June $10^{\text {th }}, 2012$ 
diabetes and hypertension drug that satisfy thresholds the minimum effective level (Minimum Effective Concentration; MEC) and maximum toxic levels (Minimum Toxic Concentration; MTC) of each drug.

Keywords - Fuzzy Inference System, Pareto Optimality, Drug Interaction.

\section{PENDAHULUAN}

$\mathrm{O}$ bat merupakan elemen yang sangat penting untuk mencegah maupun mengobati penyakit dan keluhan kesehatan. Pesatnya kemajuan teknologi dalam pengembangan obat baru memungkinkan pasien untuk memperoleh pengobatan yang tepat, efektif dan efisien, namun juga mengandung resiko yang dapat membahayakan keselamatan pasien. Hampir setiap orang pernah minum obat, tetapi mungkin banyak yang tidak menaruh perhatian terhadap obat yang dikonsumsi. Banyak orang minum obat bebas atau obat yang diresepkan dokter tanpa mempedulikan kemungkinan timbulnya efek samping dari obat yang diminum.

Salah satu faktor yang dapat mengubah respon obat-obat adalah pemberian secara bersamaan dengan obat-obat lain. Interaksi obat atau yang lebih dikenal dengan istilah drug interaction merupakan interaksi yang terjadi antar obat yang di konsumsi secara bersamaan. Interaksi obat dapat menghasilkan efek baik terhadap pasien, namun tidak jarang menghasilkan efek buruk, sehingga hal ini merupakan salah satu penyebab banyak terjadinya kesalahan pengobatan. Secara umum, kesalahan pengobatan akibat interaksi obat jarang terungkap akibat kurangnya pengetahuan terhadap efek samping yang ditimbulkan.

Terapi yang optimal memerlukan penentuan jenis obat secara tepat termasuk dosisnya. Tercapainya kadar optimal mempunyai arti bahwa kadar obat di dalam darah berada dalam kisaran terapi, yaitu tidak melampaui kadar toksik minimal (KTM) sehingga tidak menimbulkan efek samping atau efek toksik, dan tidak berada di bawah kadar efektif minimal (KEM) yang menyebabkan kegagalan terapi[1].

Pelayanan informasi obat sebagai salah satu bentuk pelayanan farmasi klinis diarahkan untuk mengoptimalkan kualitas medis. Pelayanan farmasi klinis bertujuan untuk memastikan bahwa pasien dapat menerima obat yang rasional, yakni sesuai dengan kebutuhan pasien, sehingga diharapkan dapat mengurangi risiko reaksi obat yang tidak dikehendaki yang mungkin terjadi. Interaksi obat dapat menyebabkan reaksi obat yang tidak dikehendaki apabila potensi terjadinya interaksi tersebut tidak diketahui sebelumnya sehingga tidak dapat dilakukan upayaupaya optimalisasi. Potensi interaksi obat dengan mempertimbangkan risk and benefit agar dapat mengatasi kemungkinan terjadinya potensi interaksi[2].

Banyak masalah optimisasi memerlukan perancang untuk mengoptimisasi sejumlah objektif yang bermasalah. Objektif - objektif tersebut bertentangan satu dengan yang lainnya jika sebuah peningkatan dalam satu objektif menimbulkan kemunduran pada yang lain. Penelitian tersebut mengkaji secara teoritis permasalahan linier dan non linier dengan menerapkan metode pareto front untuk menyelesaikan optimisasi pada permasalahan multi objektif. Sistem yang dibuat dan dirancang pada saat input fungsi objektif dan kendala, baik yang bersifat linier ataupun non linier dan merupakan multi objektif maka akan diselesaikan dengan pareto front dengan hasil yang diperoleh berupa numerik dan grafik[3].

Penyakit dan efek obat adalah sesuatu yang tidak bisa di tentukan secara pasti seberapa pengaruhnya. Penyakit hipertensi dan diabetes merupakan faktor resiko berbagai penyakit seperti stroke, serangan jantung, gagal jantung dan aneurisma arterial, gagal jantung dan sebagainya, untuk mengurangi kemungkinan timbulnya penyakit tersebut dapat dilakukan dengan mengontrol tekanan darah pada penderita hipertensi dan untuk penderita penyakit diabetes dilakukan dengan mengontrol kadar gula darah agar tetap dalam keadaan normal. Hal ini tentu diperlukan obat yang dapat menjaga agar tekanan darah dan gula darah selalu dalam keadaan normal.

IJCCS Vol. 6, No. 1, January 2012: 23-32 
Penelitian ini menggunakan metode Fuzzy Inference Sistem (FIS) untuk menentukan obat yang sesuai untuk menjaga agar tekanan darah penderita penyakit hipertensi dan kadar gula darah penderita diabetes tetap terkontrol dalam keadaan normal. Solusi yang baik dari pemberian obat yang berhubungan dengan resep obat dengan mempertimbangkan efek interaksi antar obat dan tidak membuat efek interaksi obat yang lain menjadi lebih buruk. Solusi optimal dapat ditentukan jika tidak terjadi konflik yaitu timbul efek interaksi obat yang negatif, namun jika terjadi konflik maka solusi optimalnya adalah solusi optimal pareto, untuk itu Pareto Optimality yang digunakan untuk menentukan solusi optimal penggunaan obat.

\section{METODE PENELITIAN}

Sistem yang di bangun akan menggunakan dua metode yaitu Fuzzy Inference System untuk menentukan obat yang akan digunakan untuk kondisi penyakit tertentu dan Metode Optimasi menggunakan pareto optimality dalam menyelesaikan optimalitas penggunaan dua obat secara bersama. Adapun langkah demi langkah tahapan jalannya sistem yang dibuat yaitu :

1. Input data yang dibutuhkan sistem, yaitu data obat.

2. User menginputkan kondisi tekanan darah sistolik dan diastolik serta kadar glukosa darah untuk menentukan tingkat penyakit hipertensi dan diabetes.

3. User memilih dua obat yang akan di gunakan secara bersama dari data obat yang tersedia.

4. Berdasarkan obat yang telah dipilih maka dibuat model matematika untuk menghitung optimalitas penggunaan obat tersebut.

5. Perhitungan optimasi menghasilkan kombinasi 2 obat untuk penyakit hipertensi dan diabetes yang dapat di gunakan oleh user sebagai acuan penggunaan obat, hasil di tampilkan dalam tabel hasil optimasi dan secara grafik. Flowchart sistem dapat dilihat pada Gambar 1

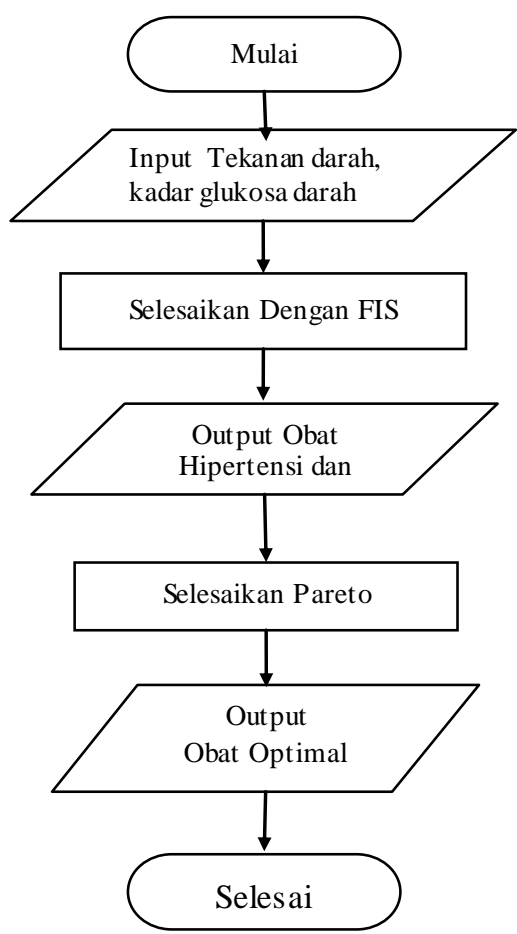

Gambar 1. Flowchart Sistem

\subsection{Konstruksi FIS}

Himpunan fuzzy yang dibuat untuk tiap-tiap variabel input terlihat pada Tabel 1 Fungsi derajat keanggotaan yang digunakan pada tiap variabel fuzzy ditentukan berdasarkan klasifikasi tingkat penyakit. Derajat keanggotaan $(\mu)$ untuk setiap himpunan fuzzy mempunyai interval dari 
0 sampai dengan 1. Nilai 1 menunjukkan kanggotaan mutlak (100\%) sedangkan hilai 0 menunjukkan tidak adanya keanggotaan $(0 \%)$ di dalam himpunan fuzzy tersebut.

Tabel 1 Himpunan Input Fuzzy

\begin{tabular}{|c|c|c|c|}
\hline \multicolumn{2}{|c|}{ Variabel } & \multicolumn{2}{|c|}{ Himpunan input fuzzy } \\
\hline Nama & Notasi & Nama & Domain \\
\hline \multirow{4}{*}{$\begin{array}{c}\text { Tekanan Darah } \\
\text { Sistolik }\end{array}$} & \multirow{4}{*}{ hs } & Normal & {$[90,130]$} \\
\hline & & Pre-hipertensi & {$[120,140$} \\
\hline & & Hipertensil & {$[135,165$} \\
\hline & & Hipertensi2 & {$[155,200$} \\
\hline \multirow{4}{*}{$\begin{array}{c}\text { Tekanan Darah } \\
\text { Diastolik }\end{array}$} & \multirow{4}{*}{ hd } & Normal & {$[60,80]$} \\
\hline & & Pre-hipertensi & {$[75,95]$} \\
\hline & & Hipertensil & {$[90,105$} \\
\hline & & Hipertensi2 & {$[100,120$} \\
\hline \multirow{4}{*}{$\begin{array}{c}\text { Kadar Glukosa } \\
\text { Darah }\end{array}$} & \multirow{4}{*}{$\mathrm{dp}$} & Normal & {$[90,120]$} \\
\hline & & Ringan & {$[110,180$} \\
\hline & & Sedang & {$[170,220$} \\
\hline & & Berat & {$[200,300$} \\
\hline
\end{tabular}

Tabel 2 Himpunan Output Fuzzy

\begin{tabular}{|c|c|c|c|}
\hline \multicolumn{2}{|c|}{ Variabel } & \multicolumn{2}{|c|}{ Himpunan input fuzzy } \\
\hline Nama & Notasi & Nama & Domain \\
\hline \multirow{3}{*}{$\begin{array}{c}\text { Golongan Obat } \\
\text { Hipertensi }\end{array}$} & \multirow{4}{*}{ gh } & ACE I & {$[0,25]$} \\
\cline { 3 - 4 } & & ARB & {$[20,45]$} \\
\cline { 3 - 4 } & & Diuretik & {$[40,65]$} \\
\cline { 3 - 4 } & & Beta Blocker & {$[60,85]$} \\
\cline { 3 - 4 } & & CCB & {$[80,100]$} \\
\hline \multirow{4}{*}{$\begin{array}{c}\text { Golongan Obat } \\
\text { Diabetes }\end{array}$} & \multirow{4}{*}{ Gd } & Sulfonilurea & {$[0,25]$} \\
\cline { 3 - 4 } & & Tiazolidindion & {$[20,45]$} \\
\cline { 3 - 4 } & & $\begin{array}{c}\text { Penghambat } \alpha- \\
\text { glukosidase }\end{array}$ & {$[40,65]$} \\
\cline { 3 - 4 } & & Biguanida & {$[60,85]$} \\
\cline { 3 - 4 } & & Insulin & {$[80,100]$} \\
\hline
\end{tabular}

Fungsi derajat keanggotaan dari variabel tekanan darah sistolik di definisikan persamaan:

$$
\begin{aligned}
& \frac{(h s-90)}{100-90}, \quad 90 \leq h s \leq 100 \\
& \mu_{\text {Normal }}(h s)=\begin{array}{rr}
1, & 100 \leq h s \leq 120 \\
\frac{(130-h s)}{130-120}, & 120 \leq h s<130
\end{array} \\
& \text { 0, } \underset{(h s-120)}{h s} \leq 90 \text { atau } h s \geq 130 \\
& \frac{(h s-120)}{130-120}, 120 \leq h s<130 \\
& \mu_{\text {prehipertensi }} h s=\frac{(140-h s)}{140-130}, 130 \leq h s<140 \\
& 0 \text {, hs } \leq 120 \text { atau hs } \geq 140 \\
& \frac{(h s-135)}{140-135}, \quad 135 \leq h s \leq 140 \\
& \mu_{\text {Hipertensi } 1}(h s)=\begin{array}{rr}
1, & 140 \leq h s \leq 150 \\
\frac{(165-h s)}{165-150}, & 150 \leq h s \leq 165
\end{array} \\
& 0, \quad h s \leq 135 \text { atau } h s \geq 165 \\
& \frac{(h s-155)}{160-155}, 155 \leq h s \leq 160
\end{aligned}
$$

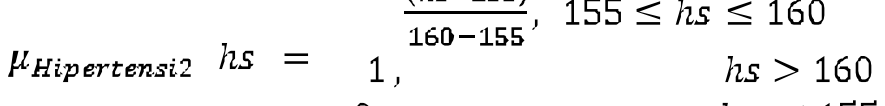

Fungsi derajat keanggotaan dari variabel tekanan darah diastolik di definisikan persamaan:

IJCCS Vol. 6, No. 1, January 2012: 23-32 


$$
\begin{aligned}
& \frac{(h d-60)}{65-60}, \quad 60 \leq h d \leq 65 \\
& \begin{aligned}
1, & 65 & \leq h d \leq 75 \\
\mu_{\text {Normal }}(h d)= & \frac{(80-h d)}{80-75}, & 75 \leq h d \leq 80
\end{aligned} \\
& 0 \text {, } \quad h d \leq 60 \text { atau } h d \geq 80 \\
& \frac{(h d-75)}{90-75}, 75 \leq h d<90 \\
& \mu_{\text {prehipertensi }} h d=\frac{(95-h d)}{95-90}, 90 \leq h d<95 \\
& 0 \text {, hd }<75 \text { atau hd }>95 \\
& \frac{(h d-90)}{95-90}, \quad 90 \leq h d \leq 95 \\
& \mu_{\text {Hipertensi } 1}(h d)=\begin{aligned}
1, & 95 \leq h d \leq 100 \\
\frac{(105-h d)}{105-100}, & 100 \leq h d \leq 105
\end{aligned} \\
& 0, \quad \text { hd } \leq 90 \text { atau } h d \geq 105 \\
& \frac{(h d-100)}{110-100}, 100 \leq h d \leq 110 \\
& \mu_{\text {Hipertensi } 2} h d=1,{ }^{110-100} \quad \text { hd }>110 \\
& 0, \quad h d<100
\end{aligned}
$$

Fungsi derajat keanggotaan dari variabel kadar glukosa darah di definisikan persamaan

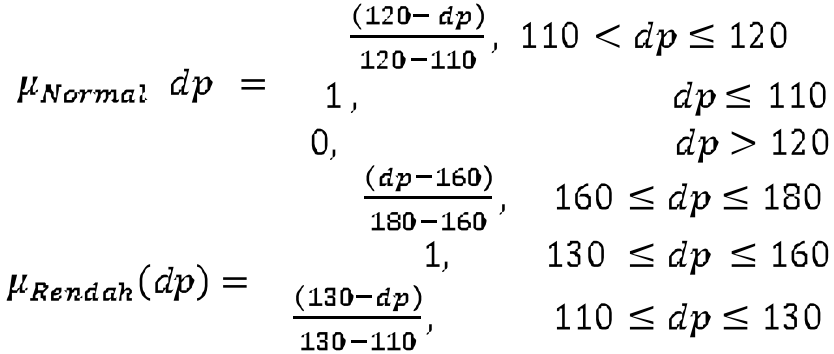

$$
\begin{aligned}
& 0, \quad d p \leq 110 \text { atau } d p \geq 180 \\
& \frac{(d p-170)}{200-170}, 170 \leq d p<200 \\
& \mu_{\text {Sedang }} d p=\frac{(220-d p)}{220-200}, 200 \leq d p<220 \\
& 0, d p \leq 170 \text { atau } d p \geq 220 \\
& \mu_{\text {Berat }} d p=\begin{array}{ll}
\frac{(d p-200)}{230-200}, 200 \leq d p \leq 230 \\
1, & d p>230 \\
0, & d p<200
\end{array}
\end{aligned}
$$

Secara umum rules dibuat oleh pakar berdasarkan teori dan praktek dilapangan. Rules berupa pernyataan-pernyataan kualitatif yang ditulis dalam bentuk IF THEN, sehingga mudah di mengerti. Rules pada FIS penelitian ini diperoleh dari teori praktis tentang penyakit hipertensi dan diabetes serta pendapat dari dokter.

\subsection{Model Matematika Interaksi Obat}

Model matematika dibuat berdasarkan obat yang dipilih oleh pengguna dari golongan tertentu sesuai dengan kondisi penyakit, masing-masing obat memiliki data yang berbeda, oleh sebeb itu model matematika yang terbentuk berbeda untuk setiap obat.

Parameter farmakokinetika suatu obat dapat mengalami perubahan karena terjadinya interaksi suatu obat dengan obat lain di dalam tubuh pada pemakaian secara bersamaan atau berurutan. Interaksi obat didefinisikan sebagai suatu keadaan bilamana suatu obat di pengaruhi oleh penambahan obat lain dan mendapat pengaruh klinis. Akibat dari interaksi tersebut dapat 
berupa efek obat ataupun perubahan proses farmakokinetika dan farmakodinamika masingmasing obat.

Untuk beberapa obat, hubungan antara jumlah obat yang diberikan dan efeknya entitas, disebut sebagai farmakodinamika, sering dimodelkan oleh fungsi sigmoid. Model farmakodinamik dinyatakan sebagai fungsi dari konsentrasi kompartemen efek. Sebuah kurva sigmoid dapat diadopsi untuk menggambarkan baik efek positif dan negatif farmakodinamik obat. Untuk satu obat, model dapat diringkas dalam persaman berikut:[4]

$$
\begin{gathered}
E=E_{\text {max }} \cdot \frac{\left(\frac{C}{E C_{50}}\right)^{\gamma}}{1+\left(\frac{C}{E C_{50}}\right)^{\gamma},} \\
E_{N}=E_{\text {max }} \cdot \frac{\left(\frac{C}{E C_{50 N}}\right)^{\gamma_{N}}}{1+\left(\frac{C}{E C_{50 N}}\right)^{\gamma / N},}
\end{gathered}
$$

dimana $\mathrm{E}_{\max }$ adalah efek individu obat positif dan $\mathrm{E}_{\operatorname{maxN}}$ adalah efek individu obat negatif; $\mathrm{EC}_{50}$ dan $\mathrm{EC}_{50 \mathrm{~N}}$ adalah dosis obat yang dibutuhkan untuk mencapai $50 \%$ dari efek positif dan negatif maksimum; $\gamma$ dan $\gamma_{\mathrm{N}}$ adalah parameter modulasi kemiringan kurva sigmoid masing-masing positif dan negatif; $\mathrm{C}$ adalah konsentrasi obat dalam kompartemen efek.

Dalam kasus administrasi gabungan dari dua atau lebih obat, potensi interaksi harus dipertimbangkan, di mana kombinasi obat dianggap sebagai obat baru yang mempunyai hubungan farmakodinamik sigmoid sendiri. Model ini disebut sebagai Minto model. Minto Model diperluas untuk memperhitungkan interaksi yang timbul dari efek negatif. Untuk pemahaman yang lebih baik dari perluasan yang diusulkan, aspek-aspek utama dari model Minto secara singkat diringkas dalam kombinasi dua obat, tetapi model ini umumnya berlaku untuk kombinasi dari dua obat atau lebih. Kombinasi dua obat didefinisikan oleh rasio konsentrasi normalisasi $(\theta)$ yaitu:

$$
\begin{gathered}
\theta=\frac{U_{B}}{U_{A}+U_{B}}, \\
U_{A}=\frac{C_{A}}{E C_{50,4}} \\
U_{B}=\frac{C_{B}}{E C_{50, s}},
\end{gathered}
$$

dimana $\mathrm{U}_{\mathrm{A}}$ dan $\mathrm{U}_{\mathrm{B}}$ adalah konsentrasi dinormalisasi masing-masing obat $\mathrm{A}$ dan $\mathrm{B}$, dan rasio obat ( $\theta$ berkisar dari 0 hingga 1). Menurut pendekatan Minto Model, efek positif dari kombinasi dapat dimodelkan oleh relasi farmakodinamik sigmoid dimana parameter adalah fungsi dari rasio obat, parameter farmakodinamik individu masing-masing obat, dan parameter lainnya yang menggambarkan efek interaksi. Penelitian ini terdapat dua fungsi tujuan yaitu efek positif dan efek negatif, efek positif dirumuskan dalam persamaan

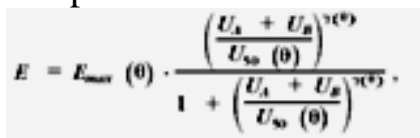

dimana parameter farmakodinamik global dapat dinyatakan dari fungsi parameter farmakodinamik obat tunggal, rasio obat $(\theta)$ dan parameter interaksi $\left(\beta_{\mathrm{i}}\right)$

$$
\begin{array}{ccc}
E_{\max }(\theta) & =E_{\max A}+\left(E_{\max B}-E_{\max A}-\beta_{E}\right) \cdot \theta+\beta_{E} \cdot \theta^{2} \\
\gamma(\theta) & = & \gamma_{A}+\left(\gamma_{B}-\gamma_{A}-\beta_{\gamma}\right) \cdot \theta+\beta_{\gamma} \cdot \theta^{2} \\
U_{50}(\theta) & = & 1-\beta_{V_{50}} \cdot \theta+\beta_{U_{50}} \cdot \theta^{2}
\end{array}
$$

dengan memperluas pendekatan ini, maka untuk efek negatif dirumuskan dalam persamaan

IJCCS Vol. 6, No. 1, January 2012 : 23 - 32 


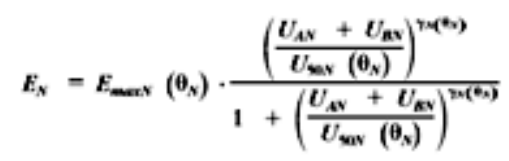

dimana

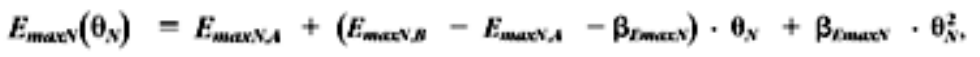

$$
\begin{aligned}
& \gamma_{S}\left(\theta_{N}\right)=\gamma_{S A}+\left(\gamma_{N B}-\gamma_{N A}-\beta_{Y S}\right) \cdot \theta_{N}+\beta_{\gamma_{N}} \cdot \theta_{N}^{2}, \\
& U_{\text {so }}\left(\theta_{N}\right)=1-\beta_{\text {Usav }} \cdot \theta_{N}+\beta_{\text {Usav }} \cdot \theta_{N}^{2},
\end{aligned}
$$

Rasio $\theta_{\mathrm{N}}$ didefinisikan dengan :

$$
\begin{aligned}
& \boldsymbol{\theta}_{N}=\frac{U_{\mathrm{Av}}}{U_{A V}+U_{\mathrm{RV}}}, \\
& U_{A v}=\frac{C_{A}}{E C_{\text {sav } A}} \text {. } \\
& U_{n s}=\frac{C_{u}}{E C_{\text {savs }}},
\end{aligned}
$$

dengan pendekatan ini, parameter obat yang diberikan hanya terbatas parameter interaksi yang diperlukan dalam rangka untuk menghitung fungsi kesehatan untuk memperoleh efek yang dihasilkan. Keuntungan utama dari pendekatan ini adalah dengan keterbatasan yang ditetapkan oleh efek negatif ke dalam ekspresi untuk fungsi kesehatan, "jangkauan optimal" dari kompartemen konsentrasi efek dapat diidentifikasi sebagai set konsentrasi yang mengarah ke maksimum atau setidaknya untuk nilai fungsi kesehatan yang memadai.

\subsection{Komputasi Pareto}

Ketika menghitung Pareto Front, dua penyelesaian dibandingkan dan penyelesaian yang didominasi dikeluarkan dari kumpulan kandidat pengoptimal Pareto. Oleh sebab itu, Pareto Front terdiri dari penyelesaian-penyelesaian yang tidak didominasi. [5]

Untuk memproses, beberapa notasi dibutuhkan. Misalkan

$$
x^{*^{r}}=\boldsymbol{*}_{1}^{*^{r}}, x_{2}^{*^{r}}, x_{3}^{*^{r}}, \ldots ., x_{n}^{*^{r}} \bar{T}
$$

Buatlah ke-r sebagai kandidat penyelesaian optimal Pareto, $\mathrm{r}=1,2, \ldots, \mathrm{R}$, di mana $\mathrm{R}$ adalah jumlah kandidat penyelesaian Pareto. Misalkan

$$
f\left(x^{* r}\right)=f_{1}\left(x_{1}^{* r}\right), f_{2}\left(x_{2}^{* r^{r}}\right), f_{3}\left(x_{3}^{*^{r}}\right), \ldots . ., f_{l}\left(x_{n}^{*^{* r}}\right)_{-}^{\bar{T}}
$$

Perhitungan nilai vektor fungsi obyektif, untuk suatu kandidat penyelesaian baru $\mathrm{x}^{\mathrm{j}}$, evaluasi vektor fungsi obyektif $\boldsymbol{f}\left(x^{j}\right)$, kemudian bandingkan kandidat penyelesaian baru dengan penyelesaian-penyelesaian Pareto yang ada.

Perlu dipertimbangkan tiga hal:

- $\quad \mathrm{x}^{\mathrm{j}}$ mendominasi setidaknya satu kandidat penyelesaian.

- $\quad \mathrm{x}^{\mathrm{j}}$ tidak mendominasi kandidat-kandidat penyelesaian yang lain.

- $\quad \mathrm{x}^{\mathrm{j}}$ didominasi oleh satu kandidat penyelesaian.

Jika $\mathrm{x}^{\mathrm{j}}$ mendominasi setidaknya satu kandidat penyelesaian, penyelesaian yang didominasi tersebut harus dihapus dari kumpulan penyelesaian tersebut dan tambahkan penyelesaian yang baru $\mathrm{x}^{\mathrm{j}}$ ke kumpulan kandidat. Kasus kedua, saat kandidat penyelesaian baru $\mathrm{x}^{\mathrm{j}}$ tidak mendominasi kandidat penyelesaian Pareto yang lain, tambahkan penyelesaian Pareto yang baru tersebut ke dalam kumpulan kandidat penyelesaian Pareto. Kasus ketiga, ketika kandidat penyelesaian yang baru didominasi oleh paling tidak satu kandidat penyelesaian Pareto yang ada, maka tidak boleh mengubah kumpulan kandidat penyelesaian Pareto yang ada. 
Algoritma untuk membangkitkan Pareto Front yang mengimplementasikan ide-ide yang awal/yang terlebih dahulu. Algoritma ini adalah sebuah modifikasi minor dari algoritma Osyczka (91, pp. 100-101).

Misalkan $\mathrm{J}$ merupakan jumlah kandidat penyelesaian yang dicek/diperiksa sebagai untuk pengoptimalisasian, sementara $\mathrm{R}$ adalah jumlah kandidat penyelesaian Pareto saat ini. Ingatlah bahwa 1 adalah jumlah fungsi obyektif, dimensi vektor fungsi obyektif, dan $\mathrm{n}$ adalah dimensi ruang keputusan, yang adalah, jumlah dari komponen x. Algoritma terdiri dari delapan langkah.

Algoritma untuk membangkitkan sebuah Pareto Front:

1. Bangkitkan sebuah inisial penyelesaian $x^{1}$ dan evaluasi $f^{* 1}=f\left(x^{1}\right)$. Penyelesaian pertama yang digeneretkan ini diambil sebagai sebuah kandidat penyelesaian Pareto. Kumpulan inisial mengindikasikan $\mathrm{R}:=1$ dan $\mathrm{j}:=1$.

2. Atur $\mathrm{j}=\mathrm{j}+1$. Jika $\mathrm{j} \leq \mathrm{J}$, kemudian generetkan penyelesaian $\mathrm{x}^{\mathrm{j}}$ dan lanjutkan ke langkah 3. Sebaliknya, berhenti, karena semua penyelesaian kandidat sudah dipertimbangkan.

3. Atur $\mathrm{r}:=1$ dan $\mathrm{q}:=0$ ( $\mathrm{q}$ mewakili jumlah penyelesaian-penyelesaian yang dikeluarkan dari kumpulan penyelesaian Pareto yang ada).

4. Jika untuk semua $\mathrm{i}=1,2, \ldots, 1$,

$$
f i\left(x^{j}\right)<f i\left(x^{* r}\right)
$$

Kemudian kumpulan $\mathrm{q}:=\mathrm{q}+1, \mathrm{f}^{* \mathrm{R}}:=\mathrm{f}\left(\mathrm{x}^{\mathrm{j}}\right)$, penyelesaian tersebut yang seharusnya dikeluarkan/dieliminasi, dan lanjutkan ke langkah 6.

5. Jika untuk semua $\mathrm{i}=1,2, \ldots, \mathrm{l}$,

$$
f i\left(x^{j}\right) \geq f i\left(x^{* r}\right)
$$

Selanjutnya lanjutkan ke langkah 2 .

6. Atur $r:=r+1$. Jika $r \leq R$, lanjutkan ke langkah 4 .

7. Jika $\mathrm{q} \neq 0$, hapuslah dari kumpulan kandidat Pareto yang di eliminer pada langkah 4 , tambahkan penyelesaian $\mathrm{x}^{\mathrm{j}}$ sebagai kandidat baru penyelesaian Pareto, dan lanjutkan ke langkah 2.

8. Atur $\mathrm{R}:=\mathrm{R}+1, \mathrm{x}^{* \mathrm{R}}:=\mathrm{x}^{\mathrm{j}}, \mathrm{f}^{* \mathrm{R}}:=\mathrm{f}\left(\mathrm{x}^{\mathrm{j}}\right)$, dan lanjutkan ke langkah 2 .

\section{HASIL DAN PEMBAHASAN}

Proses FIS dalam mencari nilai pemakaian obat yang sesuai dengan kondisi pasien contoh kasus : Seorang pasien X menderita penyakit hipertensi dan diabetes, setelah diukur tekanan darah sistolik yaitu 140, tekanan darah diastolic 80, dan kadar gula darah 220 pasien X bermaksud mengkonsumsi obat agar dapat menurunkan tekanan darahnya dan kadar gula darah menjadi normal, adapun tampilan untuk masukan seperti pada Gambar 2

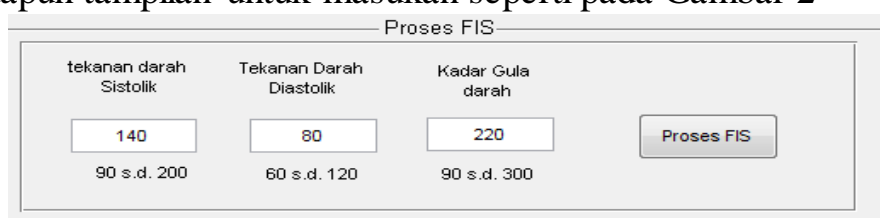

Gambar 2 Tampilan input untuk proses FIS

Langkah pertama yang dilakukan adalah mencari derajat keanggotaan fuzzy pada setiap variabel input yaitu:

1. Tekanan darah Sistolik jika tekanan darah sistolik $=140$ maka derajat keanggotaan fuzzy adalah :

$\mu_{\text {Hipertensi1 }} h s=1$,

2. Tekanan darah diastolik

jika tekanan darah diastolik $=80$ maka derajat keanggotaan fuzzy adalah :

$\mu_{\text {Normal }}(h d)=0$

IJCCS Vol. 6, No. 1, January 2012 : 23-32 
$\mu_{\text {prenipertensi }} h d=\frac{80-75}{90-75}=0.333$

3. Kadar gula darah

jika kadar gula darah $=220$ maka derajat keanggotaan fuzzy adalah :

$\mu_{\text {isdang }}(d p)=0$

$u_{\text {Berat }} d p=\frac{220-200}{230-200}=0.667$

Langkah kedua adalah menerapkan fungsi implikasi untuk mendapatkan modifikasi output daerah fuzzy dari setiap rule yang berlaku. Ada dua fungsi yang sering digunakan dalam proses implikasi yaitu min (minimum) dan prod (product). Fungsi implikasi yang digunakan dalam tesis ini adalah metode Min ( $\alpha$-cut).

Fungsi Min memilih yang terkecil antara dua bilangan atau lebih hasil operasi fuzzy logic.

$\alpha_{40}=\mu_{\text {Hipertensi1 }} h s \Lambda \mu_{\text {prehipertensi }}$ hd $\Lambda \mu_{\text {Berat }} d p$

$\alpha_{40}=\min \left(\mu_{\text {Hipertensi1 }} 140 \Lambda \mu_{\text {prehipertensi }} 80 \Lambda \mu_{\text {Berat }} 220\right)$

$\alpha_{40}=\min (1,0.333,0.667)=0.333($ Beta Blocker, Insulin $)$

Nilai Z untuk Output Golongan Obat Hipertensi $=63.33$ (Beta Blocker) dan Nilai Z untuk Output Golongan Obat Diabetes = 83.33(Insulin)

Dalam kasus diatas pasien akan mengkonsumsi obat diabetes ACTRAPIS HM dari golongan insulin dan obat hipertensi LETONAL dari golongan Beta Blocker, dari obat yang dipilih, maka akan dibuat model matematika untuk perhitungan optimasi. Fungsi efek positif f1 (maksimal),

Fungsi efek positif f2 (minimal),

$$
f 1(C A, C B)=\frac{(C A+5 C B)^{\left(10-\frac{5 C A}{C A+5 C E}\right)}}{C A+5 C B^{\left(10-\frac{5 C A}{C A+5 C B}\right)}+1}
$$

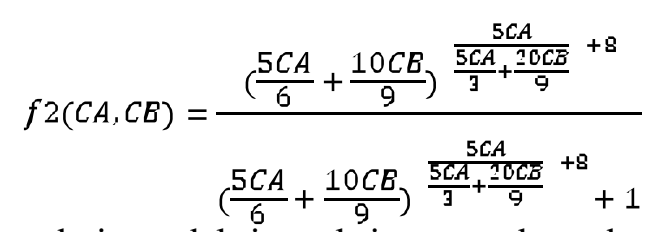

Model matematika dari model interaksi antar dua obat merupakan multiobyektif nonlinier, kedua fungsi obyektif mempunyai bentuk nonlinier yaitu fungsi pertama yang akan dimaksimalkan f1(CA,CB) dan fungsi kedua merupakan fungsi yang akan diminimalkan f2(CA,CB), fungsi kendala juga bersifat nonlinier, untuk menyelesaikan masalah multiobyektif nonlinier, digunakan pendekatan pareto optimal untuk memperoleh pasangan nilai optimal untuk f1 dan f2.

Hasil optimasi pareto terdapat sekumpulan titik-titik yang merupakan hasil optimasi, namun dalam kasus ini perbedaaan dari pasangan titik-titik solusi tidak signifikan sehingga pareto front yang diperoleh hanya ada satu titik. Pareto front yaitu titik yang paling mendominasi merupakan solusi yang optimal, dari titik tersebut di peroleh CA dan CB, CA dan CB untuk masing-masing obat seperti terlihat pada Gambar 3.

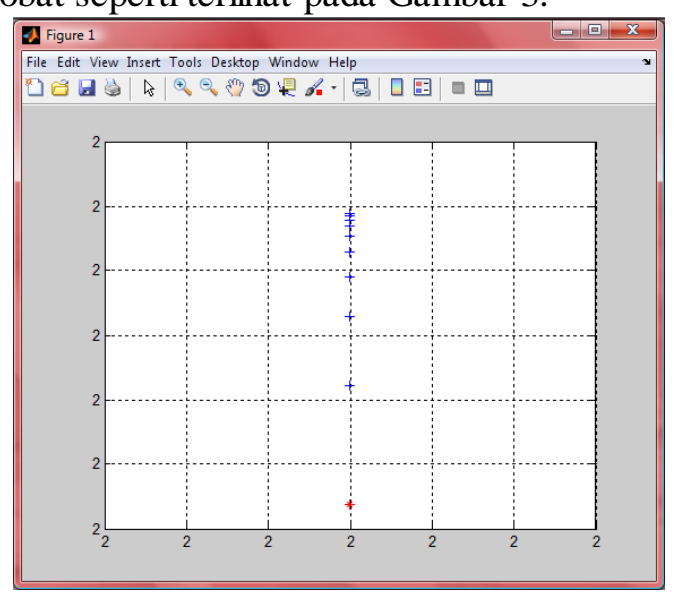

Gambar 3 Tampilan grafik hasil optimasi pareto 
Kondisi tekanan darah sistolik 140 , tekanan darah diastolic 80 , dan kadar gula darah 220. Obat pilihan obat diabetes ACTRAPIS HM dari golongan obat insulin dan obat hipertensi dari golongan Beta Blocker, diperoleh CA yaitu konsentrasi obat ACTRAPIS HM sebesar 0.7800 dan CB yaitu konsentrasi obat LETONAL sebesar 4.6600 maka untuk penggunaan obat tersebut dosis disesuaikan dengan konsentrasi masing-masing obat, sehingga dapat menghasilkan terapi optimal untuk kedua penyakit hipertensi dan diabetes.

\section{KESIMPULAN} berikut:

Berdasarkan pembahasan pada bab-bab sebelumnya maka diambil kesimpulan sebagai

1. Proses Fuzzy Inference System didasarkan pada kondisi penyakit pasien pada saat itu yaitu dari hasil pengukuran tekanan darah dan kadar gula darah sehingga didapatkan output pilihan golongan obat sesuai dengan kondisi penyakit pasien.

2. Interaksi obat dapat diselesaikan dengan menggunakan pareto optimality yang menghasilkan pasangan nilai solusi optimal yang memenuhi batasan nilai kadar minimal efektif (Minimum Effective Concentration; MEC) dan kadar toksik maksimum (Minimum Toxic Concentration; MTC) masing-masing obat.

3. Solusi akhir diperoleh dari output yang dihasilkan pada proses Fuzzy Inference System sehingga pilihan obat pasien didasarkan pada golongan obat yang sesuai dengan kondisi pasien, dan optimalitas pengunaan obat yaitu dari pasangan nilai solusi optimal pareto.

\section{SARAN}

Untuk pengembangan penelitian selanjutnya, Perhitungan solusi optimal pada penelitian ini hanya terbatas pada interaksi antar dua obat, selanjutnya di harapkan dapat mengembangkan pada interaksi tiga obat atau lebih, dapat juga mengembangkan penentuan solusi optimal interaksi obat dengan makanan.

\section{DAFTAR PUSTAKA}

[1] Haryanti, S., 2004, Evaluasi Penggunaan Dosis Antibiotika dan Interaksi Obat pada pasien Gagal Ginjal Kronik di Empat Rumah Sakit di Jogjakarta Periode Januari-Juni 2004, Tesis, Magister Farmasi Klinik Universitas Gadjah Mada, Yogyakarta.

[2] Sari, Andriana., 2010, Pengaruh Pelayanan Informasi Obat Terhadap Potensi Interaksi Obat pada Pasien Rawat Inap Penyakit Dalam di RSUD Prof.Dr.Margono Soekarjo Purwokerto Periode Maret - Agustus 2010, Tesis, Magister Farmasi Klinik Universitas Gadjah Mada, Yogyakarta.

[3] Hiswati, Marselina E., 2010, Optimasi Multi Obyektif pada Fungsi Linier Menggunakan Pareto Front, Tesis, S2 Ilmu Komputer Universitas Gadjah Mada, Yogyakarta.

[4] Zanderigo, E., Valentina, S., Gorazd, Thomas, B., Peter, S., Michele, C., Manfred, M., 2005, A New Model for Drug Interactions and Optimal Drug Dosing, Proceeding, Engineering in Medicine and Biology $27^{\text {th }}$ Annual Conference, China.

[5] Chong, E.K.P dan Zak, S.H, 2008, An Introduction to Optimization, Third edition, John Wiley \& Sons, New York.

IJCCS Vol. 6, No. 1, January 2012 : 23-32 